\title{
Impact of Total Protein Level and Dysglycaemia on the Efficacy of Clopidogrel in Patients Underwent Carotid Artery Stenosis with CYP2C19 Genetic Variants
}

\section{Sijia Hao}

Genetic Diagnosis Center, The First Hospital of Jilin University

Xinyuan $\mathrm{Hu}$

Genetic Diagnosis Center, The First Hospital of Jilin University

Zhongxi Yang

Neurovascular Surgery, The First Hospital of Jilin University

Haoyuan Yin

Neurovascular Surgery, The First Hospital of Jilin University

Yanjiao Li

Department of Clinical Pharmacy, The First Hospital of Jilin University

Xinlu Wang

Department of Clinical Pharmacy, The First Hospital of Jilin University

Yuhao Zhao

Neurovascular Surgery, The First Hospital of Jilin University

Jianmin Piao

Neurovascular Surgery, The First Hospital of Jilin University

Xuan Chen

Neurovascular Surgery, The First Hospital of Jilin University

Yanfang Jiang ( $\sim$ jiangyanfang456@126.com )

Genetic Diagnosis Center, The First Hospital of Jilin University

\section{Research Article}

Keywords: CYP2C19, MACCEs, cerebral artery stent, cerebral artery stenosis, clopidogrel

Posted Date: July 30th, 2021

DOI: https://doi.org/10.21203/rs.3.rs-745056/v1

License: (1) This work is licensed under a Creative Commons Attribution 4.0 International License. Read Full License 


\section{Abstract}

BACKGROUND: CYP2C19polymorphisms are associated with the increased risk of major adverse cardiovascular/cerebrovascular events (MACCEs) in cerebral intervention. In this study, we wanted to investigate whether the CYP2C19 polymorphism and other nongenetic factors can influence the incidence of MACCEs in cerebral artery stenosis disease patients.

METHODS: A total of 164 patients underwent cerebral artery stenting and 138 patients underwent conservative treatment among 1406 who patients underwent CYP2C19 gene screening and were enrolled in this study. A Cox proportional hazards model and Kaplan-Meier analyses were used to assess the predictive value of CYP2C19 loss-of-function (LOF) allele $(* 2, * 3)$ carrier status and other risk factors.

RESULTS: The CYP2C19*1/*1 genotype was observed to be the most predominant among the patients $(41.96 \%)$. The patients who underwent conservative treatment and had glucose levels $>6.5 \mathrm{mmol} / \mathrm{L}$ were more likely to experience MACCEs $(p=0.022)$. CYP2C19 LOF allele variants $(p=0.032)$, total protein $<65$ $g / L(p=0.017)$ and glucose $>6.5 \mathrm{mmol} / \mathrm{L}(\mathrm{p}=0.028)$ were associated with an increased risk of MACCEs in patients who underwent cerebral artery stents in the multivariable Cox analysis.

CONCLUSION: CYP2C19 polymorphisms, total protein levels and glucose can impact the risk of MACCEs in patients who undergo cerebral artery stents.

\section{Introduction}

Cerebral artery stenosis is an important risk factor for ischaemic stroke ${ }^{1}$ and can be divided into combined intracranial and extracranial arterial stenosis, intracranial arterial stenosis, and extracranial arterial stenosis ${ }^{2}$.The treatment of cerebral artery stenosis, including conservative treatment, carotid endarterectomy (CEA) and carotid artery stenting (CAS), is most commonly used in cerebral artery stenosis treatment.Meanwhile, dual antiplatelet therapy (DAPT) with aspirin and clopidogrel has been recommended for cerebral artery stenosis to reduce thromboembolic events ${ }^{3}$.

Clopidogrel, which is an orally administered prodrug, can be converted into an active metabolite by hepatic cytochrome P450 (CYP) ${ }^{4}$, and CYP2C19 is an important metabolizing enzyme.Among the 25 genetic variants of $C Y P 2 C 19$, the wild-type $C Y P 2 C 19^{*} 1$ allele is associated with functional $C Y P 2 C 19$-mediated metabolism, while CYP2C19*2 (c.681G > A; rs4244285) and *3(c.636G >A; rs4986893) alleles, which are the major CYP2C19 loss-of-function (LOF) variant alleles, can reduce the level of clopidogrel active metabolites in the blood and induce a decrease in clopidogrel function, resulting in inhibition of platelet aggregation ${ }^{4-7}$.

It has been reported that CYP2C19 polymorphism is involved in major adverse cardiovascular/cerebrovascular events (MACCEs) of cerebral intervention ${ }^{8}$.The CYP2C19 polymorphism influencing the incidence of MACEs has been widely studied in coronary heart disease patients. It has been reported that patients with CYP2C19 LOF variant alleles who have undergone percutaneous coronary intervention $(\mathrm{PCl})$ are more likely to experience MACCEs ${ }^{9}$, and $5-30 \%$ of $\mathrm{PCl}$ patients cannot respond to clopidogrel $^{10,11}$. However, whether the CYP2C19 polymorphism can influence the incidence of MACCEsin 
moderate-severe cerebral artery stenosis disease patients remains unknown.Additionally, many other factors can influence the incidence of MACCEs after cerebral artery stenosis, including patient clinical characteristics such as dysglycaemia ${ }^{12}$ and eGFR ${ }^{13}$.

In this study, to assess the risk predictors of the risk of MACCEs after cerebral artery stenosis, we analysed the potential predictive value of risk predictors such as CYP2C19 polymorphisms, liver function, kidney function and blood glucose level in the conservative treatment group and cerebral artery stent group.

\section{Materials And Methods}

\section{Ethics statement}

The Ethics Committee of First Hospital of Jilin University approved this project. All of the samples and data were collected after written informed consent was provided by the participants. The management and publication of patient information in this research was strictly in accordance with the Declaration of Helsinki,including confidentiality and anonymity.

\section{Study population}

From October 2016 to December 2019, 1406 patients underwentCYP2C19 genotype screening at the genetic diagnosis centre of First Hospital of Jilin University. A total of 362 of them were diagnosed with cerebral artery stenosis in the neurosurgery department of our hospital. As shown in Fig. 1,302 patients were finally recruited in the study on the basis of the inclusion and exclusion criteria.

The inclusion criteria were as follows:

1) Patients were diagnosed with cerebral artery stenosis and underwent conservative treatment or cerebral artery stent; 2) patients received DAPT of clopidogrel $(75 \mathrm{mg})$ and aspirin $(100 \mathrm{mg})$ for at least 6 months.

According to the CYP2C19 loss-of-function allele (LOF) gene polymorphism, patients were divided into 2 groups according to their CYP2C19 genotype: a noncarrier group and a carrier group.Patients with wild-type CYP2C19 (no mutations) $(* 1 / * 1$ ) were assigned to the noncarrier group.Patients with $C Y P 2 C 19 \star 2$ or $* 3$ were assigned to the carrier group.

MACCEs includedeath, stroke or stent thrombosis. All cerebral artery stenosis patients were diagnosed with moderate-severe cerebral artery stenosis disease. On account of status reasons, such as age factors, fragility of blood vessels and cardiac insufficiency, 143 patients could not tolerate the carotid intervention operation only orally with DAPT.

Aftercerebral artery stent operation, patients received $75 \mathrm{mg}$ clopidogrel and $100 \mathrm{mg}$ aspirin as dual antiplanet therapy for at least 6 months. Patients were followed up at 6 months. The CYP2C19 genotyping results and relevant clinical information were all recorded, including age, sex, liver function tests, kidneyfunction tests and other laboratory test values available in the database. All laboratory tests were 
performed at the First Hospital of Jilin University before treatment. Baseline variables are summarized with the use of descriptive statistics.

\section{Genetic Analysis}

We used a DNA array to screen the CYP2C19 genotypes. DNA was extracted from whole-blood samples with nucleic acid extracting reagent (BaiO Technology, Shanghai, China). The PCR program consisted of an initial step at $50{ }^{\circ} \mathrm{C}$ for $5 \mathrm{~min}, 94{ }^{\circ} \mathrm{C}$ for $5 \mathrm{~min}, 35$ cycles at $94{ }^{\circ} \mathrm{C}$ for $25 \mathrm{~s}, 48{ }^{\circ} \mathrm{C}$ for $40 \mathrm{~s}$ and $72{ }^{\circ} \mathrm{C}$ for $30 \mathrm{~s}$, and a final extension at $72{ }^{\circ} \mathrm{C}$ for $5 \mathrm{~min}$. We obtained images of the hybridization of the amplificationproducts with the gene probes. The images and data were analysed by BaiO Array Doctor Version 2.0(BaiO Technology, Shanghai, China) software.

\section{Statistical analysis}

Data analysis was performed using SPSS 20.0 software (IBM, Armonk, NY, USA) and GraphPad Prism 5. Measurement data aredisplayed as the mean \pm standard deviation, and categorical variables are expressed as the frequency and percentage. The distribution of categorical variables was compared among the study group using the chi-square test. Differences were considered statistically significant at $p<0.05$.KaplanMeier analyses were used to generate survival plots of time to MACCEs during the 6-month follow-up period, and groups were compared by the log-rank test. Differences between the conservative treatment group and cerebral artery stent group in terms of the rate of MACCEs during the 6-month follow-up were assessed by a Cox proportional hazards regression model. Multivariable Cox regression analyses were adjusted by age, sex, AST,creatinine and BUN as a random effect. The interaction of CYP2C19 LOF allele carrierstatus with risk factors such as $A L T$, total protein and glucose was analysed by the above crude and multivariableCox models. Two-sided $\mathrm{P}<0.05$ was considered statistically significant.

\section{Results}

As shown in Fig. 1, the detailed patient selection process was described.From October 2016 to December 2019, 1406 patients underwent CYP2C19 genotype screening at the genetic diagnosis centre of First Hospital of Jilin University. A total of 362 of them were diagnosed with cerebral artery stenosis in the neurosurgery department of our hospital. 143 patients only orally took DAPT. Of these, 5 patients could not be followed up and were excluded. Therefore, 138 patients who took DAPT only orally for 6 months were finally recruited as the conservative treatment group. In addition, among the 219 patients who underwent cerebral intervention, 11 patients underwent carotid endarterectomy, 5 patients died in the hospital, 18 patients did not receive $75 \mathrm{mg}$ clopidogrel for economic reasons and adverse effects, and 11 patients could not be followed up. Thus, a total of 55 patients were excluded from this study. Finally, 164 patients who underwent cerebral artery stenting and orally took DAPT for 6 months were recruited as the cerebral artery stent group.

\section{Distribution of the CYP2C19 genotype in patients}

The frequency of the $C Y P 2 C 19{ }^{\star} 2$ and $* 3$ alleles did not deviate significantly from Hardy-Weinberg equilibrium. The frequencies of the CYP2C19*1, *2 and *3 alleles in all patients are shown in Fig. 2. We 
found that the CYP2C19*1/*1 genotype was the most predominant among the patients $(41.96 \%)$, followed by CYP2C19*1/*2 (39.69\%). The frequency of the CYP2C19*2 (comprising *1/*2, *2/*2, and *2/*3) allele was $30.75 \%$, and that of the $* 3$ (comprising $* 1 / * 3, * 2 / * 3$, and $* 3 / * 3$ ) allele was $4.77 \%$.According to whether they carried CYP2C19LOF alleles, we divided the 1406 patients into 2 groups according to their CYP2C19 genotype: noncarriers and carriers. Patients with wild-type CYP2C19 (no mutations) were assigned to the noncarriers. Patients with $C Y P 2 C 19 \star 2$ or $* 3$ were assigned to the carriers.

\section{Patient Baseline Characteristic}

The baseline characteristics among individuals who orally took DAPT and underwent cerebral artery stenting by experiencing MACCEs are shown in Table 1.Patient demographics, medical history, CYP2C19 genotyping results and laboratory values were included in the analysis. In the conservative treatment group and cerebral artery stent group, there were no significant differences between the patients with and without MACCEs in age, sex, hypertension, diabetes mellitus, smoking or drinking. In the conservative treatment group, the glucose of the patients who experienced MACCEs was significantly higher than that of the non-MACCE patients $(p=0.007)$. There was no significant difference in the frequency of CYP2C19 LOF alleles $(p=0.536)$ in the conservative treatment group regardless of whether the patients experienced MACCEs. In addition, in the cerebral artery stent group, the frequency of CYP2C19 LOF alleles $(p=0.049)$ and the ALT $(p=0.019)$ of the patients who experienced MACCEs was significantly higher than that of the non-MACCE patients, and the total protein was significantly lower $(p=0.002)$.

Table1 . Baseline Characteristics Among Individuals underwent conservative treatment and carotid artery stent by experience MACCEs or not. 


\begin{tabular}{|c|c|c|c|c|c|c|}
\hline & \multicolumn{3}{|c|}{$\begin{array}{l}\text { Conservative treatment } \\
\text { group }(n=138)\end{array}$} & \multicolumn{3}{|c|}{$\begin{array}{l}\text { Cerebral artery stent group } \\
(n=164)\end{array}$} \\
\hline & $\begin{array}{l}\text { MACCEs } \\
(n=20)\end{array}$ & $\begin{array}{l}\text { Non- } \\
\text { MACCEs }(n \\
=118)\end{array}$ & $\mathbf{P}$ & $\begin{array}{l}\text { MACCEs } \\
(n=15)\end{array}$ & $\begin{array}{l}\text { Non- } \\
\text { MACCEs } \square \mathrm{n}= \\
149 \square\end{array}$ & $\mathbf{P}$ \\
\hline Age, (yrs) & $59.15 \pm 9.67$ & $61.80 \pm 10.16$ & 0.263 & $58.87 \pm 9.33$ & $61.05 \pm 9.62$ & 0.402 \\
\hline Male, n (\%) & $15(75.00)$ & 87 (73.73) & 0.905 & $12(80.00)$ & $123(82.55)$ & 0.805 \\
\hline \multicolumn{7}{|l|}{$\begin{array}{l}\text { Medical history, } \\
\mathrm{n}[\% \square\end{array}$} \\
\hline Hypertension & $12(60.00)$ & 49 (41.53) & 0.124 & $8(57.14)$ & $88(58.67)$ & 0.912 \\
\hline Diabetes mellitus & 3 & 14 & 0.693 & 2 & 35 & 0.439 \\
\hline Smoking & 6 & 24 & 0.333 & 7 & 59 & 0.402 \\
\hline Drinking & 4 & 11 & 0.156 & 5 & 48 & 0.526 \\
\hline \multicolumn{7}{|l|}{$\begin{array}{l}\text { CYP2C19 genotyping } \\
\text { results }\end{array}$} \\
\hline$* 1 / * 1$ & $7(35.00)$ & $51(43.22)$ & 0.705 & $2(13.33)$ & $66(44.29)$ & 0.097 \\
\hline$* 1 / * 2$ & $9(45.00)$ & 44 (37.29) & & $8(53.33)$ & $52(34.89)$ & \\
\hline *1/*3 & $1(5.00)$ & $10(8.47)$ & & $1(6.67)$ & $9(6.04)$ & \\
\hline$\star 2 / * 2$ & $1(5.00)$ & 8 (6.78) & & $4(5.24)$ & $16(10.74)$ & \\
\hline$\star 2 / * 3$ & $1(5.00)$ & 4 (3.39) & & $0(0.00)$ & $6(4.04)$ & \\
\hline$\star 3 / * 3$ & $1(5.00)$ & $1(0.85)$ & & $0(0.00)$ & $0(0.00)$ & \\
\hline Noncarriers & $7(35.00)$ & $51(43.22)$ & 0.536 & $2(13.33)$ & 66 (44.29) & 0.049 \\
\hline Carriers & $13(65.00)$ & $67(56.78)$ & & 13 (86.67) & $83(52.71)$ & \\
\hline \multicolumn{7}{|l|}{ Laboratory values } \\
\hline $\operatorname{ALT}(\mathrm{U} / \mathrm{L})$ & $19.94 \pm 8.54$ & $26.66 \pm 20.73$ & 0.156 & $31.59 \pm 21.12$ & $24.03 \pm 10.10$ & 0.019 \\
\hline AST (U/L) & $20.29 \pm 13.20$ & $25.57 \pm 18.10$ & 0.215 & $35.67 \pm 35.98$ & $26.18 \pm 19.63$ & 0.107 \\
\hline ALP (U/L) & $61.56 \pm 25.49$ & $73.57 \pm 30.49$ & 0.106 & $90.74 \pm 30.35$ & $78.14 \pm 25.60$ & 0.076 \\
\hline $\begin{array}{l}\text { Total } \\
\text { Protein (g/L) }\end{array}$ & $64.79 \pm 5.70$ & $65.69 \pm 6.98$ & 0.590 & $60.41 \pm 7.39$ & $65.33 \pm 5.54$ & 0.002 \\
\hline Albumin $(\mathrm{g} / \mathrm{L})$ & $41.48 \pm 8.44$ & $40.36 \pm 7.92$ & 0.567 & $36.61 \pm 4.49$ & $38.36 \pm 3.60$ & 0.081 \\
\hline $\begin{array}{l}\text { Total Bilirubin } \\
(\mu \mathrm{mol} / \mathrm{L})\end{array}$ & $14.11 \pm 10.85$ & $13.88 \pm 8.70$ & 0.921 & $9.33 \pm 5.09$ & $12.66 \pm 6.83$ & 0.068 \\
\hline Indirect Bilirubin & $8.23 \pm 4.18$ & $8.91 \pm 4.49$ & 0.554 & $6.25 \pm 4.00$ & $9.51 \pm 7.21$ & 0.087 \\
\hline
\end{tabular}




\begin{tabular}{|lllllll|}
\hline$(\mu \mathrm{mol} / \mathrm{L})$ & & & & & \\
\hline Glucose $(\mathrm{mmol} / \mathrm{L})$ & $6.98 \pm 3.13$ & $5.70 \pm 1.63$ & 0.007 & $6.83 \pm 1.96$ & $6.24 \pm 2.32$ & 0.346 \\
\hline $\begin{array}{l}\text { Creatinine } \\
(\mu \mathrm{mol} / \mathrm{L})\end{array}$ & $64.1 \pm 25.38$ & $68.16 \pm 24.76$ & 0.526 & $69.3 \pm 17.38$ & $73.8 \pm 15.83$ & 0.316 \\
\hline $\mathrm{BUN}(\mathrm{mmol} / \mathrm{L})$ & $13.4 \pm 22.49$ & $9.76 \pm 15.80$ & 0.395 & $5.50 \pm 1.71$ & $5.66 \pm 1.46$ & 0.692 \\
\hline
\end{tabular}

\section{CYP2C19 LOF allele variants, ALT levels, total protein levels and blood glucose levels are associated with an increased risk of MACCEs in patients who underwent cerebral artery stents}

To identify the influencing factors of the clinical endpoint after cerebral artery stenosis, we performed logrank tests.As shown in Table 2, in the conservative treatment group, we found that the patients whose glucose level was higher than $6.5 \mathrm{mmol} / \mathrm{L}$ were more likely to experience MACCEs $(p=0.022)$. In the cerebral artery stent group, we found that patients carrying CYP2C19 LOF alleles (*2 and *3) were more likely to experience MACCEsthan noncarriers $(p=0.020)$. We also found that the rates of MACCEs were significantly higher in patients whose ALT was higher than $35 \mathrm{U} / \mathrm{L}(p=0.022)$,total proteinwas lower than $65 \mathrm{~g} / \mathrm{L}(\mathrm{p}=$ $0.020)$ or glucose was higher than $6.5 \mathrm{mmol} / \mathrm{L}(\mathrm{p}=0.019)$. 
Table 2

Association between baseline characteristics and risk of MACCEs at 6 months in conservative treatment group and cerebral artery stent group

\begin{tabular}{|c|c|c|c|c|c|}
\hline Characteristics & Group & $\begin{array}{l}\text { The MACCEs rate of } \\
\text { conservative treatment } \\
\text { group }\end{array}$ & $\begin{array}{l}\text { P value } \\
\text { (log- } \\
\text { rank) }\end{array}$ & $\begin{array}{l}\text { The MACCEs rate of } \\
\text { cerebral artery stent } \\
\text { group }\end{array}$ & $\begin{array}{l}\text { P value } \\
\text { (log- } \\
\text { rank) }\end{array}$ \\
\hline \multirow[t]{2}{*}{ Age } & $<65 \mathrm{yrs}$ & 14/101 (1.27) & 0.168 & $12 / 117(10.26)$ & 0.427 \\
\hline & $>65 \mathrm{yrs}$ & 6/37 (16.22) & & $3 / 47$ (6.38) & \\
\hline \multirow[t]{2}{*}{ Sex } & Male & $15 / 102(14.70)$ & 0.682 & 12/135 (8.89) & 0.828 \\
\hline & Female & 5/36 (13.89) & & $3 / 29(10.34)$ & \\
\hline \multirow{2}{*}{$\begin{array}{l}\text { CYP2C19 } \\
\text { genotypes }\end{array}$} & Noncarriers & $7 / 58$ (12.07) & 0.453 & $2 / 68(2.94)$ & 0.020 \\
\hline & Carriers & $13 / 80(16.25)$ & & $13 / 96(13.54)$ & \\
\hline \multirow[t]{2}{*}{ AST } & $<40 \mathrm{U} / \mathrm{L}$ & $18 / 120(15.00)$ & 0.750 & $12 / 145(8.28)$ & 0.286 \\
\hline & $>40 \mathrm{U} / \mathrm{L}$ & $2 / 16(12.50)$ & & $3 / 19$ (15.79) & \\
\hline \multirow[t]{2}{*}{ ALT } & $<35 \mathrm{U} / \mathrm{L}$ & 19/118 (16.10) & 0.239 & $11 / 146$ (7.53) & 0.032 \\
\hline & $>35 \mathrm{U} / \mathrm{L}$ & 1/18 (5.56) & & $4 / 18(2.22)$ & \\
\hline \multirow[t]{2}{*}{ Total Protein } & $<65 \mathrm{~g} / \mathrm{L}$ & $10 / 67(14.93)$ & 0.947 & $12 / 84(14.29)$ & 0.020 \\
\hline & $>65 \mathrm{~g} / \mathrm{L}$ & $10 / 68$ (14.70) & & $3 / 80(3.75)$ & \\
\hline \multirow[t]{2}{*}{ Albumin } & $<40 \mathrm{~g} / \mathrm{L}$ & $13 / 90(14.44)$ & 0.938 & $12 / 118(10.17)$ & 0.493 \\
\hline & $>40 \mathrm{~g} / \mathrm{L}$ & $7 / 45(15.56)$ & & $3 / 45$ (6.67) & \\
\hline \multirow[t]{2}{*}{ Glucose } & $\begin{array}{l}<6.5 \\
\mathrm{mmol} / \mathrm{L}\end{array}$ & 11/104 (10.58) & 0.022 & $6 / 109$ (5.50) & 0.019 \\
\hline & $\begin{array}{l}>6.5 \\
\mathrm{mmol} / \mathrm{L}\end{array}$ & $9 / 34(26.47)$ & & 9/55 (16.36) & \\
\hline \multirow[t]{2}{*}{ Creatinine } & $\begin{array}{l}<60 \\
\mu \mathrm{mol} / \mathrm{L}\end{array}$ & 6/39 (15.38) & 0.862 & 5/34 (14.71) & 0.175 \\
\hline & $\begin{array}{l}>60 \\
\mu \mathrm{mol} / \mathrm{L}\end{array}$ & $12 / 87(13.79)$ & & $10 / 129(7.75)$ & \\
\hline \multirow[t]{2}{*}{ BUN } & $\begin{array}{l}<6.5 \\
\mathrm{mmol} / \mathrm{L}\end{array}$ & $9 / 85$ (10.59) & 0.086 & $10 / 116(8.62)$ & 0.709 \\
\hline & $\begin{array}{l}>6.5 \\
\mathrm{mmol} / \mathrm{L}\end{array}$ & 9/41 (21.95) & & $5 / 47(10.64)$ & \\
\hline
\end{tabular}

Dysglycaemia may influence the predictive value of CYP2C19 loss-of-function alleles in patients who underwent cerebral artery stents 
To further investigate how the influencing factors impact the predictive value of CYP2C19 LOF alleles, we generated Kaplan-Meier curves to assess the association of CYP2C19 LOF alleles and the incidence of MACCEs stratified by patient status. We found that the CYP2C19 LOF alleles were identified as a predictor of MACCEs at 6 months after carotid artery stenting only when the patients had glucose levels $>6.5 \mathrm{mmol} / \mathrm{L}(\mathrm{p}$ $=0.0260)$ (Fig. 3).

\section{CYP2C19 LOF allele variant, total protein level and dysglycaemiasynergically impact the risk of MACCEs in patients who underwent cerebral artery stents}

To further investigate the relationship between CYP2C19 LOF allele carriers and patient status with MACCE risk, the Cox proportional hazards regression model was used to assess the association.

As shown in Table 3, the univariable analysis revealed that glucose $>6.5 \mathrm{mmol} / \mathrm{L}(p=0.033)$ was significantly associated with MACCEs at 6 months in the conservative treatment group.Similarly, onlyglucose $>6.5 \mathrm{mmol} / \mathrm{L}(p=0.010)$ remained significant in the multivariable Cox analysis. Nevertheless, the univariable analysis revealed that CYP2C19 genotypes $(p=0.037), A L T>35 \mathrm{U} / L(p=0.033)$, total protein $<65 \mathrm{~g} / \mathrm{L}(\mathrm{p}=0.030)$ and glucose $>6.5 \mathrm{mmol} / \mathrm{L}(\mathrm{p}=0.028)$ were significantly associated with MACCEs at 6 months inthe cerebral artery stent group (Table 4$)$. We found that CYP2C19 genotypes $(p=0.032)$,total protein $<65 \mathrm{~g} / \mathrm{L}(\mathrm{p}=0.017)$ and $(p=0.028)$ remained significant in the multivariable Cox analysis (Table 4).Collectively, these results indicated that CYP2C19 LOF allele variants, total protein levels and dysglycaemiasynergically increase the risk of MACCEs. 
Table 3

Association between baseline characteristics and risk of MACCEs at 6 months in 138 patients only take DAPT medicine

\begin{tabular}{|c|c|c|c|c|}
\hline \multirow[t]{3}{*}{ Characteristics } & \multicolumn{4}{|c|}{ Conservative treatment group $(n=138)$} \\
\hline & \multicolumn{2}{|c|}{ MACCEs at 6 months (Bivariable) } & \multicolumn{2}{|c|}{ MACCEs at 6 months (Multivariable) } \\
\hline & $\mathrm{HR}(95 \% \mathrm{Cl})$ & $\mathbf{P}$ & $\mathrm{HR}(95 \% \mathrm{Cl})$ & $\mathbf{P}$ \\
\hline Age $>65$ yrs & $1.214(0.466,3.158)$ & 0.692 & $1.453(0.517-4.083)$ & 0.479 \\
\hline Male & $0.894(0.325,2.459)$ & 0.828 & $1.727(0.498-5.991)$ & 0.389 \\
\hline CYP2C19 genotypes & $1.404(0.56,3.519)$ & 0.469 & $1.026(0.379-2.780)$ & 0.959 \\
\hline AST $>40$ & $0.795(0.185,3.427)$ & 0.758 & $0.944(0.192-4.635)$ & 0.944 \\
\hline ALT > $35 \mathrm{U} / \mathrm{L}$ & $0.329(0.044,2.457)$ & 0.279 & $0.196(0.023-1.704)$ & 0.140 \\
\hline Total protein $>65 \mathrm{~g} / \mathrm{L}$ & $0.972(0.404,2.335)$ & 0.972 & $1.082(0.379-3.084)$ & 0.883 \\
\hline Albumin $<40 \mathrm{~g} / \mathrm{L}$ & $1.036(0.413,2.597)$ & 0.940 & $0.947(0.302-2.966)$ & 0.925 \\
\hline Glucose $>6.5$ & $2.604(1.079,6.284)$ & 0.033 & $4 \llbracket 077(1.396-11.912)$ & 0.010 \\
\hline Creatinine $>60 \mu \mathrm{mol} / \mathrm{L}$ & $0.919(0.345,2.449)$ & 0.866 & $1.997(0.561-7.105)$ & 0.285 \\
\hline BUN > 6.5 MMOL/L & $2.149(0.853,5.414)$ & 0.105 & $2.144(0.772-5.954)$ & 0.143 \\
\hline
\end{tabular}


Table 4

Association between baseline and treatment characteristics and risk of MACCEs at 6 months in 164 patients underwent cerebral artery stent group

\begin{tabular}{|lllll|}
\hline \multirow{2}{*}{ Characteristics } & \multicolumn{3}{l}{ Cerebral artery stent group $(\mathbf{n}=164)$} & \\
\cline { 2 - 5 } & \multicolumn{2}{l}{ MACCEs at 6 months (Bivariable) } & MACCEs at 6 months (Multivariable) \\
\cline { 2 - 5 } & HR (95\% Cl) & P & HR (95\% Cl) & P \\
\hline Age $>65$ yrs & $0.604(0.171-2.142)$ & 0.436 & $0.703(0.191-2.587)$ & 0.596 \\
\hline Male & $1.149(0.324-4.071)$ & 0.830 & $0.972(0.241-3.913)$ & 0.968 \\
\hline CYP2C19 genotypes & $4.863(1.097-21.551)$ & 0.037 & $5.295(1.157-24.226)$ & 0.032 \\
\hline AST > 40 U/L & $1.956(0.552-6.933)$ & 0.299 & $2.403(0.613-9.416)$ & 0.208 \\
\hline ALT > 35 U/L & $3.235(1.030-10.161)$ & 0.033 & $3.193(0.790-12.901)$ & 0.103 \\
\hline Total protein <65 g/L & $0.253(0.071-0.895)$ & 0.030 & $0.127(0.023-0.691)$ & 0.017 \\
\hline Albumin < 40 g/L & $0.647(0.183-2.293)$ & 0.500 & $0.535(0.146-1.953)$ & 0.344 \\
\hline Glucose $>6.5$ & $3.181(1.132-8.939)$ & 0.028 & $3.283(1.139-9.464)$ & 0.028 \\
\hline Creatinine $>60 ~ \mu \mathrm{mol} / \mathrm{L}$ & $0.486(0.166-1.422)$ & 0.188 & $0.383(0.113-1.294)$ & 0.122 \\
\hline BUN $>6.5 \mathrm{mmol} / \mathrm{L}$ & $1.224(0.418-3.581)$ & 0.712 & $1.530(0.501-4.667)$ & 0.455 \\
\hline
\end{tabular}

\section{Discussion}

We analysed the CYP2C19 genotype screening results of 1406 patients genotyped at the genetic diagnosis centre of the First Hospital of Jilin University from October 2016 to December 2019, and the frequency of CYP2C19LOF variant allele carriers was 58.04\%. Furthermore, the allelic frequencies of CYP2C19 variants display significant interethnic differences ${ }^{7}$. In Asian countries, CYP2C19LOF variant allele carriers are observed at a relatively high frequency ${ }^{14,15}$, and the frequencies of the CYP2C19*2 and *3 alleles in Chinese Han populations are significantly higher than those in other racial groups ${ }^{7}$. A previous study reported that the allele frequency of CYP2C19LOF variant allele carriers is $62.38 \%$ in China ${ }^{16}$. The results of our study are similar to the frequencies of the variant alleles CYP2C19*2 and *3 reported in previous studies.

The rate of MACCEs in the conservative treatment group was 14.49\%, and that in the cerebral artery stent groupwas 9.14\% (Table S1). A 403-patient study showed that MACCEs were observed in $8.19 \%$ of patients after treatment with $\mathrm{CAS}^{17}$, which is in line with our study. Considering the limited number of patients, the rate of MACCEs in this studymay not reflect the overall situation. This could also be driven by the patients who underwent conservative treatment, and carotid artery stents were almost all moderate-severe cerebral artery stenosis disease patients. Because conservative treatment patients whose own condition is not good enough to undergo surgery, they cannot tolerate carotid intervention operations, such as age factors, fragility of blood vessels and cardiac insufficiency, only orally. In this way, the rate of MACCEs in the conservative treatment group was higher than that in the cerebral artery stent group. 
As a commonly prescribed antiplatelet, clopidogrel is usually used to prevent secondary ischaemia in patients treated by endovascular techniques.Composite MACCE outcomes, such as death, stroke, and stent thrombosis, limit the long-term success rate of interventions through the recurrence of symptoms. Although intervention has been associated with minimal complications, previous studies have reported that CYP2C19 loss-of-function polymorphisms may be a significant risk factor for in-stent restenosis ${ }^{18}$. Clopidogrel plus aspirin is used to reduce the risk of recurrent stroke. As one of the most prominent genetic polymorphisms, CYP2C19 polymorphisms can be used to explain a poor response to clopidogrel, and CYP2C19^2 is the strongest predictor of high residual platelet reactivity ${ }^{19}$. However, few studies have reported the significance of CYP2C19polymorphismsin affecting the incidence of MACCEs aftercarotid artery stenosis, especially carotid artery stents.

It has been reported that patients with CYP2C19 LOF variant alleles have a 3.58 times higher risk for death and stroke than patients with the CYP2C19 wild-type genotype ${ }^{20}$. A recent systematic review also demonstrated that CYP2C19 loss-of-function alleles were associated with clinical outcomes for ischaemic stroke ${ }^{21}$.In addition, a previous study reported that $C Y P 2 C 19^{\star} 2$ was an independent risk factor for the primary outcomes of clopidogrel treatment in patients with acute ischaemic stroke ${ }^{22}$. In our study, the incidence of MACCEs in CYP2C19 LOF allele noncarriers $(n=343)$ was $7.14 \%(9 / 126)$, and in carriers, it was $14.69 \%$ (26/177). Patients with CYP2C19 LOF variant alleles had a 2.05 times higher risk of MACCEs than patients with the CYP2C19 wild-type genotype. Table 2 shows that there was no significant difference in the frequency of CYP2C19 LOF alleles in the conservative treatment group regardless of whether the patients experienced MACCEs. The frequency of CYP2C19 LOF alleles of the patients who experienced MACCEs was significantly higher than that of the non-MACCE patients. In the log-rank tests and multivariable Cox analysis, we found that CYP2C19 LOF allele variants were associated with an increased risk of MACCEs in patients who underwent cerebral artery stents. In this way, we infer that CYP2C19 LOF allele carriers are related to MACCE incidence in the cerebral artery stent group. These results could be driven by the fact that within conservative treatment patients, the patient's condition is so poor that the CYP2C19 gene does not work.

In addition, the baseline characteristics showed that in the conservative treatment group, the glucose of the patients who experienced MACCEs was significantly higher. In addition, in the cerebral artery stent group, the frequency of CYP2C19 LOF alleles and the ALT of the patients who experienced MACCEs was significantly higher, and the total protein was significantly lower. To identify the influencing factors of the clinical endpoint after cerebral artery stenosis, we first performed log-rank tests. We found that CYP2C19 LOF allele variants, high ALT levels, low total protein levels and high blood glucose levels were associated with an increased risk of MACCEs in patients who underwent cerebral artery stents. However, only a high blood glucose level is associated with an increased risk of MACCEs in patients who underwent conservative treatment.These findings suggested that glycaemic control was key to MACCEprevention in all carotid artery stenosis patients.In addition, we generated Kaplan-Meier curves to assess the association of CYP2C19 LOF alleles and the incidence of MACCEs stratified by patient status. We found that the CYP2C19 LOF allele carriers were identified as a predictor of the incidence of MACCEs at 6 months after carotid artery stenting only when the patients had high levels of glucose (glucose $>6.5 \mathrm{mmol} / \mathrm{L}$ ). 
A Danish cohortof nearly 60000 patients with myocardial infarction demonstrated that the clinical efficacyof clopidogrel in diabetes mellitus (DM) was impaired ${ }^{23}$. It has also been reported that DM significantly increases the risk of stroke recurrence and poor outcome in the small-artery occlusion subtype $^{22}$. In our study, the rate of MACCEs in CYP2C19 LOF allele carrierswas higher than that in noncarriers in patientswith high blood glucose levels who underwentcarotid artery stents, while in patients with normal blood glucose levels, it was not. This could be ascribed to high blood glucose levels decreasing the active metabolite of clopidogre ${ }^{24}$, especially impairing the clopidogrel clinical efficacy of CYP2C19LOF allele carriers with genetically poor clopidogrel metabolism. The mechanism of this has been reported: the active metabolite of clopidogrel could increase plateletreactivity by upregulating platelet P-selectin ${ }^{25}$ and proteinkinase $\mathrm{C}^{26}$ via the glycation of platelet surface proteinsand osmotic effects of glucose ${ }^{27}$. These findings remind usthat it is necessary to perform CYP2C19genotype tests in patients who underwent cerebral artery stents with dysglycaemia.

Next, we used the Cox proportional hazards regression model to assess the association between CYP2C19 LOF allele carriers and patient status with MACCE risk.As shown in Table 3, the univariable analysis and multivariable Cox analysis revealed that glucose $>6.5 \mathrm{mmol} / \mathrm{L}$ was significantly associated with MACCEs at 6 months in the conservative treatment group. Nevertheless, the univariable analysis revealed that CYP2C19 genotypes, ALT $>35 \mathrm{U} / \mathrm{L}$, total protein $<65 \mathrm{~g} / \mathrm{L}$ and glucose $>6.5 \mathrm{mmol} / \mathrm{L}$ were significantly associated with MACCEs at 6 months in the cerebral artery stent group (Table 4). We found that CYP2C19 genotypes, total protein $<65 \mathrm{~g} / \mathrm{L}$ and glucose $>6.5 \mathrm{mmol} / \mathrm{L}$ remained significant in the multivariable Cox analysis.

Collectively, these results indicated that CYP2C19 LOF allele variants, total protein levels anddysglycaemiasynergically impact the risk of MACCEs.On the one hand, malnutrition has an important prognostic value in patients who undergo cerebral artery stents ${ }^{28}$, and total protein $<65 \mathrm{~g} / \mathrm{L}$ may reflect themalnourished status of the patient. On the other hand, it could be due to poor kidney function, as the protein is lost in the urinary system, leading to a decrease in total protein. treatment resistance for clopidogrel. It has been reported that chronic kidney disease is associated with impaired drugabsorption and transport and platelet abnormalities, which are thought to decrease the response to clopidogrel ${ }^{11,29}$. In addition, CYP2C19 LOF wasreported to be associated with an increased risk of adverse cerebrovascularoutcomes in patients in the lowest quintile of eGFR.In this way, low total protein levels may reflect poor kidney function, and the response to clopidogrel is decreased.

In this way, we conclude that CYP2C19 LOF allele variants, total protein levels and dysglycaemia synergically impact the risk of MACCEs in patients who underwent cerebral artery stents. In addition, it is necessary to perform CYP2C19 genotype tests in patients who underwent cerebral artery stents with dysglycaemiaand low total protein levels.

There are several limitations in our study. Considering that this is a single-centre study, further multicentre and large sample studies are needed to expand upon our findings. Glucoselevels were assessed only at baseline, and a dynamic evaluationof glucose levels could be more informative. In addition, glucose levels can only reflect the current status, and glycated albumin and haemoglobin A1c can more accuratelyreflect 
the actual status of glycaemic control. Moreover, we did not assess the status of insulin resistance, which could lead to abnormal plateletP2Y12 receptor signalling in diabetic patients.

\section{Declarations}

\section{Acknowledgements}

We thank Yong Liuand Xin Shen for contribution analysis of patient samples.

\section{Contributors}

Xinyuan Hu and Sijia Hao analysed the data and performed the experiments. Sijia Hao drafted paper. Haoyuan Yin, Xinlu Wang and Zhongxi Yang, Jianmin Piao, and Yuhao Zhao selected the data. Yanjiao Li followed the patients' statement. Yanfang Jiang designed and fund the study. Xuan Chen designed and selected data.

\section{Funding}

This research was funded by the National Natural Science Foundation of China (nos. 30972610, 81273240, 91742107, and 81570002), National Key Research and Development Program (nos. 2017 YFC0910000 and 2017YFD0501300), Jilin Province Science and Technology Agency (nos. 20200403084SF, JLSWSRCZX2020-009, 20200901025SF区20190101022JH, 2019J026, 20170622009JC, 2017C021, 2017J039, SXGJXX2017-8, JJKH20180197KJ, DBXM154-2018, and 2018SCZWSZX-015).We thank the patients and their families for participating in this study.

Competing interests None declared.

Patient consent for publication Not required.

Ethics approval Research aspects of this study were approved by Ethics Committee of the First Hospital of Jilin University2016-151

Patient consent for publication Not required

Conflict of interest statement The authors declare that they have no conflicts of interest.

\section{References}

1. M, C. \& stroke, A. O. E. A. B.-L. A. J. J. o. \& Association, c. d. t. o. j. o. N. S. Intracranial arterial stenosis, 23, 599-609 https://doi.org/10.1016/j.jstrokecerebrovasdis.2013.06.006 (2014).

2. RJ, W. et al. Race and sex differences in the distribution of cerebral atherosclerosis. 27,1974-1980, doi:10.1161/01.str.27.11.1974 (1996).

3. Brott, T. G. et al. 2011 ASA/ACCF/AHA/AANN/AANS/ACR/ASNR/CNS/SAIP/SCAI/SIR/SNIS/SVM/SVS guideline on the management of patients with extracranial carotid and vertebral artery disease: executive summary. Stroke 42, e420-463, doi:10.1161/STR.0b013e3182112d08 (2011). 
4. T, Y. \& research, M. T. J. T. Pharmacogenomics of clopidogrel: evidence and perspectives, 128, 307-316 https://doi.org/10.1016/j.thromres.2011.04.010 (2011).

5. Jeong, Y. H. et al. Effect of CYP2C19*2 and *3 loss-of-function alleles on platelet reactivity and adverse clinical events in East Asian acute myocardial infarction survivors treated with clopidogrel and aspirin. Circulation. Cardiovascular interventions, 4, 585-594

https://doi.org/10.1161/circinterventions.111.962555 (2011).

6. J, A., MJ, S. K., KP, E. \& cardiology, B. H. A. \& J. T. A. j. o. Role of frailty in patients with cardiovascular disease. 103,1616-1621, doi:10.1016/j.amjcard.2009.01.375 (2009).

7. JS, J. et al. Meta-analysis of cytochrome P450 2C19 polymorphism and risk of adverse clinical outcomes among coronary artery disease patients of different ethnic groups treated with clopidogrel. 110,502-508, doi:10.1016/j.amjcard.2012.04.020 (2012).

8. W, H. et al. Impact of cytochrome P450 2C19 loss-of-function polymorphism and of major demographic characteristics on residual platelet function after loading and maintenance treatment with clopidogrel in patients undergoing elective coronary stent placement. 55,2427-2434, doi:10.1016/j.jacc.2010.02.031 (2010).

9. JL, M. et al. Reduced-function CYP2C19 genotype and risk of adverse clinical outcomes among patients treated with clopidogrel predominantly for PCl: a meta-analysis. 304,1821-1830, doi:10.1001/jama.2010.1543 (2010).

10. J, M. \& medicine, L. Z. R, L. \& J. T. N. E. j. o. Cytochrome P-450 polymorphisms and response to clopidogrel. 360,2250-2251(2009).

11. DH, L. et al. Dual antiplatelet therapy monitoring for neurointerventional procedures using a point-ofcare platelet function test: a single-center experience. 29,1389-1394, doi:10.3174/ajnr.A1070 (2008).

12. Chen, W. et al. Recurrent Stroke in Minor Ischemic Stroke or Transient Ischemic Attack With Metabolic Syndrome and/or Diabetes Mellitus. Journal of the American Heart Association, 6, https://doi.org/10.1161/jaha.116.005446 (2017).

13. Wu, Y. et al. Impact of CYP2C19 polymorphism in prognosis of minor stroke or TIA patients with declined eGFR on dual antiplatelet therapy: CHANCE substudy. The pharmacogenomics journal, 18, 713-720 https://doi.org/10.1038/s41397-018-0018-4 (2018).

14. Xie, H. G., Kim, R. B., Wood, A. J. \& Stein, C. M. Molecular basis of ethnic differences in drug disposition and response. Annual review of pharmacology and toxicology, 41, 815-850 https://doi.org/10.1146/annurev.pharmtox.41.1.815 (2001).

15. Desta, Z., Zhao, X., Shin, J. G. \& Flockhart, D. A. Clinical significance of the cytochrome P450 2 C19 genetic polymorphism. Clinical pharmacokinetics, 41, 913-958 https://doi.org/10.2165/00003088200241120-00002 (2002).

16. Zhuo, Z. L. et al. Association between CYP2C19 and ABCB1 polymorphisms and clopidogrel resistance in clopidogrel-treated Chinese patients. Anatolian journal of cardiology, 19, 123-129 https://doi.org/10.14744/AnatolJCardiol.2017.8097 (2018).

17. Liu, J. et al. Assessing risk factors for major adverse cardiovascular and cerebrovascular events during the perioperative period of carotid angioplasty with stenting patients. Experimental and therapeutic 
medicine, 12, 1039-1047 https://doi.org/10.3892/etm.2016.3360 (2016).

18. M, Z. et al. CYP2C19Impacts of Polymorphism and Clopidogrel Dosing on in-Stent Restenosis: A Retrospective Cohort Study in Chinese Patients. 14,669-676, doi:10.2147/dddt.S242167 (2020).

19. Y, P. et al. Genetic Polymorphisms and Clopidogrel Efficacy for Acute Ischemic Stroke or Transient Ischemic Attack: A Systematic Review and Meta-Analysis. 135,21-33, doi:10.1161/circulationaha.116.024913 (2017).

20. T, S. et al. Genetic determinants of response to clopidogrel and cardiovascular events. $360,363-375$, doi:10.1056/NEJMoa0808227 (2009).

21. A, G. et al. Cerebrovascular reserve and stroke risk in patients with carotid stenosis or occlusion: a systematic review and meta-analysis. 43,2884-2891, doi:10.1161/strokeaha.112.663716 (2012).

22. Pan, Y. et al. Association of Diabetes and Prognosis of Minor Stroke and Its Subtypes: A Prospective Observational Study. PloS one, 11, e0153178 https://doi.org/10.1371/journal.pone.0153178 (2016).

23. Andersson, C. et al. Association of clopidogrel treatment with risk of mortality and cardiovascular events following myocardial infarction in patients with and without diabetes., 308, 882-889 https://doi.org/10.1001/2012.jama.10779 (2012).

24. Angiolillo, D. J. et al. Impaired responsiveness to the platelet P2Y12 receptor antagonist clopidogrel in patients with type 2 diabetes and coronary artery disease. Journal of the American College of Cardiology, 64, 1005-1014 https://doi.org/10.1016/j.jacc.2014.06.1170 (2014).

25. Yngen, M., Norhammar, A., Hjemdahl, P. \& Wallén, N. H. Effects of improved metabolic control on platelet reactivity in patients with type 2 diabetes mellitus following coronary angioplasty. Diabetes \& vascular disease research, 3, 52-56 https://doi.org/10.3132/dvdr.2006.008 (2006).

26. Assert, R. et al. Regulation of protein kinase $\mathrm{C}$ by short term hyperglycaemia in human platelets in vivo and in vitro., 44, 188-195 https://doi.org/10.1007/s001250051598 (2001).

27. Keating, F. K., Sobel, B. E. \& Schneider, D. J. Effects of increased concentrations of glucose on platelet reactivity in healthy subjects and in patients with and without diabetes mellitus. The American journal of cardiology, 92, 1362-1365 https://doi.org/10.1016/j.amjcard.2003.08.033 (2003).

28. Öcal, L. et al. Prognostic significance of pre-procedural prognostic nutritional index in patients with carotid artery stenting. Journal of stroke and cerebrovascular diseases: the official journal of National Stroke Association, 29, 104932 https://doi.org/10.1016/j.jstrokecerebrovasdis.2020.104932 (2020).

29. Park, S. H. et al. A comparison of clopidogrel responsiveness in patients with versus without chronic renal failure. The American journal of cardiology, 104, 1292-1295 https://doi.org/10.1016/j.amjcard.2009.06.049 (2009).

\section{Figures}




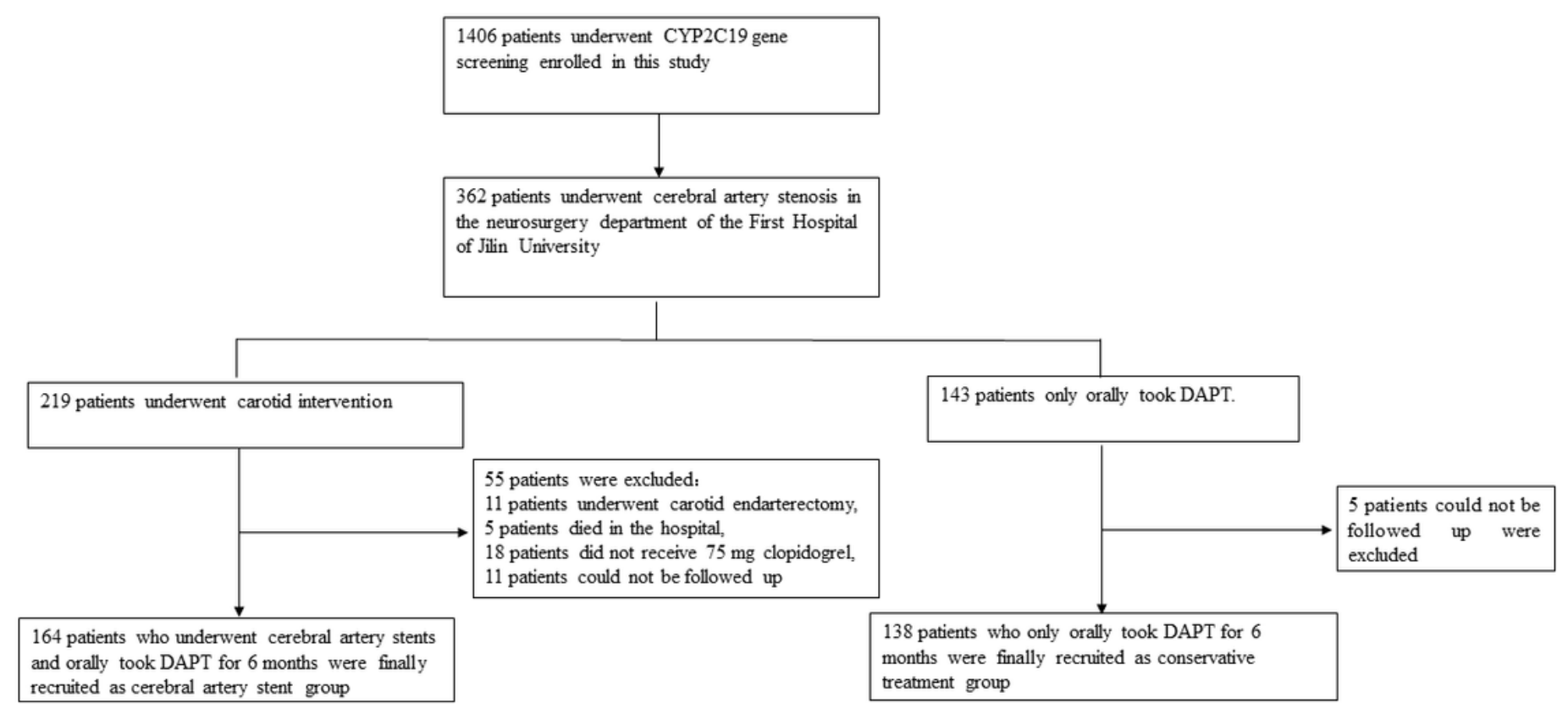

Figure 1

Flow diagram of the study population recruitment process. 


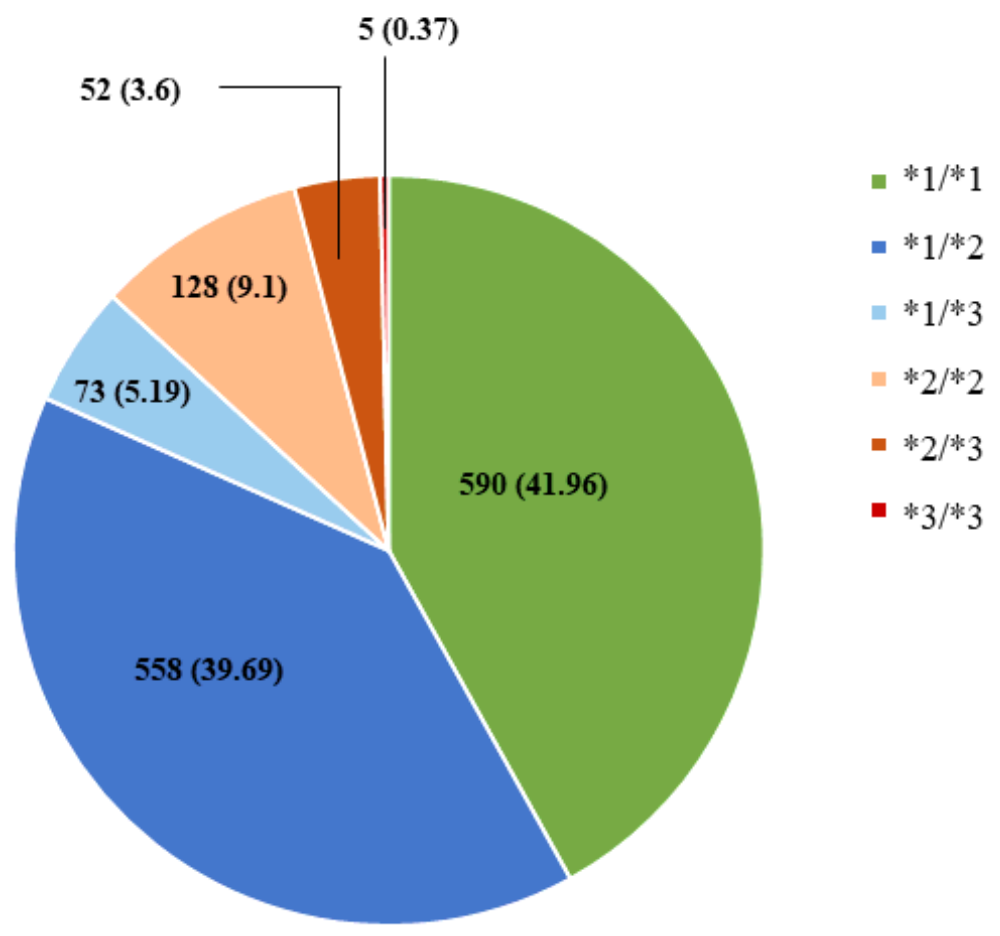

Figure 2

Distribution of the CYP2C19 genotype in patients. 
A

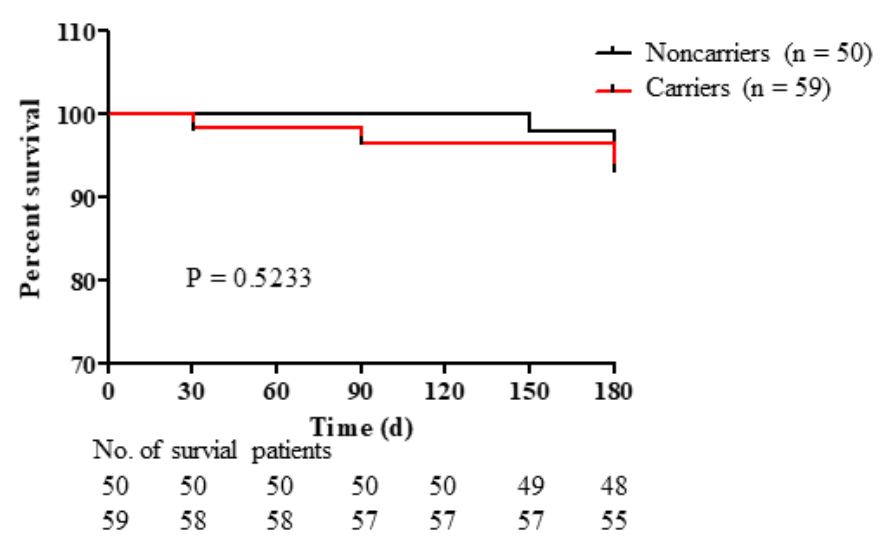

C

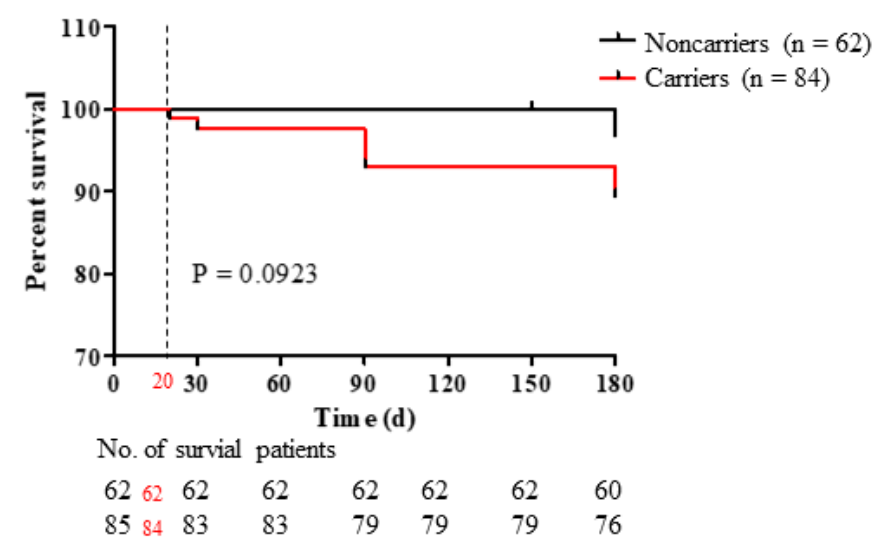

$\mathbf{E}$

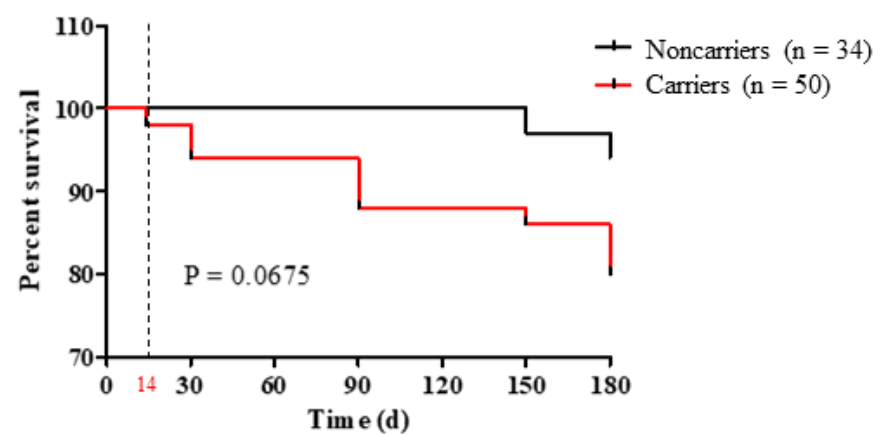

No. of survial patients

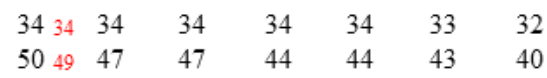

B

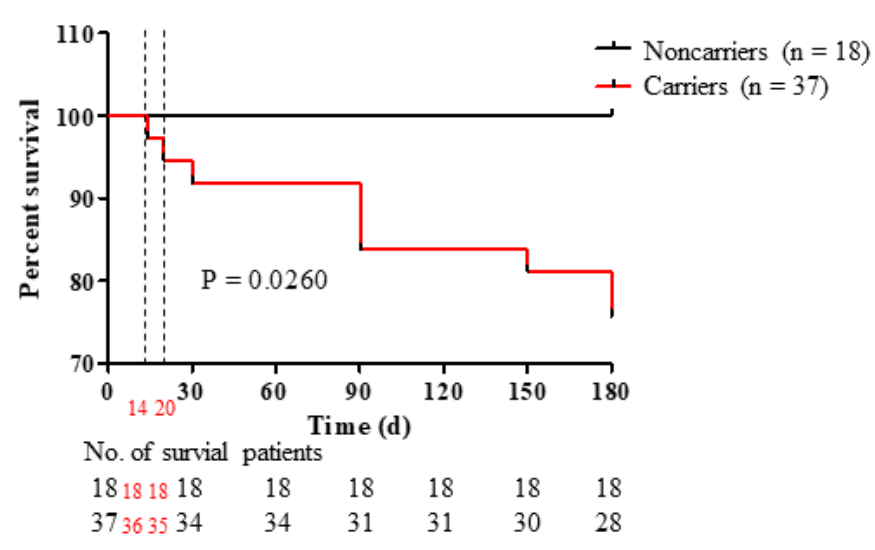

D

ALT $>35$ U/L

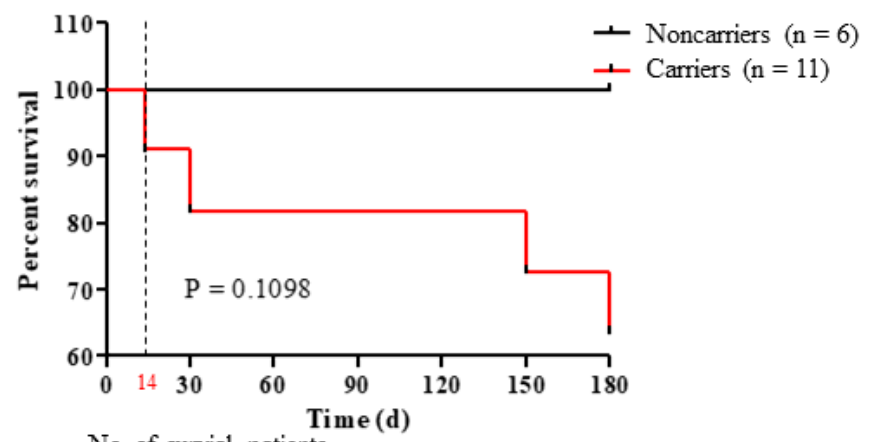

No. of survial patients

$\begin{array}{cccccccc}6 & 6 & 6 & 6 & 6 & 6 & 6 & 6 \\ 11 & 10 & 9 & 9 & 9 & 9 & 8 & 7\end{array}$

F

Total protain $>65 \mathrm{~g} / \mathrm{L}$

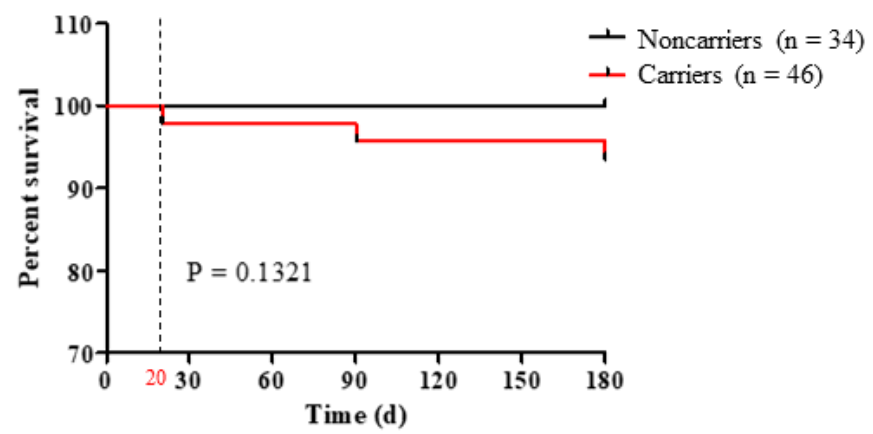

No. of survial patients

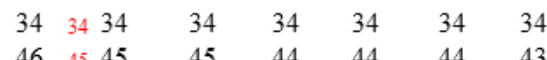

\section{Figure 3}

Rates of MACCEs over 6 months of follow-up in patients underwent cerebral artery stent. CYP2C19 LOF alleles carriers including the genotypes $* 1 / * 2, * 1 / * 3, * 2 / * 2, * 2 / * 3$ and. $* 3 / * 3$ The genotype of non-carriers is CYP2C19*1/*1. The curves represent the percentage of patients surviving at the endpoints. The numbers below the survival curves are the numbers of patients in each group who survived at the endpoints and were still at risk over the follow-up period. 


\section{Supplementary Files}

This is a list of supplementary files associated with this preprint. Click to download.

- SupplementaryMaterial.docx 